\title{
INFLUÊNCIA DE DIFERENTES PERÍODOS DE SECAGEM NA QUALIDADE FISIOLÓGICA DE SEMENTES DE Tapirira guianensis AUBLET. ${ }^{1}$
}

\author{
SUELI DA SILVA SANTOS-MOURA², EDNA URSULINO ALVES ${ }^{3}$, \\ RISELANE DE LUCENA ALCÂNTARA BRUNO³, MÁCIO FARIAS DE MOURA ${ }^{4}$, \\ PATRÍCIA SOUSA DE SALES GONDIM ${ }^{2}$
}

RESUMO - O período de viabilidade das sementes de cupiúva (Tapirira guianensis Aublet.) é muito reduzido, dificultando sua utilização pelos viveiristas. Em função da escassez de pesquisas referente à determinação do teor de água crítico para suas sementes, o trabalho teve como objetivo avaliar a qualidade fisiológica das sementes de $T$. guianensis submetidas a diferentes períodos de secagem, sob temperatura de $40{ }^{\circ} \mathrm{C}$, em estufa $(0 ; 3 ; 6 ; 9 ; 12 ; 15 ; 18 ; 21$ e 24 horas). A avaliação do efeito dos tratamentos foi realizada mediante determinação do teor de água, testes de germinação e vigor (primeira contagem $\%$ de sementes germinadas e índice de velocidade de germinação, bem como comprimento e massa seca de plântulas). Verificou-se um teor de água inicial de $36 \%$, o qual foi reduzindo com o aumento dos períodos de secagem; consequentemente, registrou-se a maior porcentagem de germinação $(97 \%)$ no período zero de secagem, reduzindo para $38 \%$ após 9 horas de secagem e, posteriormente, houve perda total da germinação. Quanto ao índice de velocidade de germinação, o maior valor $(2,93)$ ocorreu no período zero de secagem, ocorrendo o mesmo com o comprimento e a massa seca das plântulas, os quais foram reduzidos drasticamente com o aumento dos períodos de secagem. As sementes da espécie T. guianensis são recalcitrantes, perdendo a viabilidade e o vigor à medida que seu teor de água é reduzido; o nível crítico de umidade, abaixo do qual há perda total de viabilidade, está em tomo de $16 \%$.

Termos para indexação: cupiúva, sementes recalcitrantes, frutífera nativa, teor de água.

\section{INFLUENCE OF DIFFERENT PERIODS OF DRYING ON PHYSIOLOGICAL QUALITY OF TAPIRIRA GUIANENSIS AUBLET SEEDS}

\begin{abstract}
The period of viability of cupiúva seed (Tapirira guianensis Aublet.) is very short which hampers its use by nurseries. Due to the scarcity of research on the critical moisture content beyond which seeds would not germinate, this study was carried out to evaluate the physiological quality of seeds of $T$. guianensis submitted to different periods of drying conditions of $40^{\circ} \mathrm{C}$ in an oven $(0,3,6,9,12,15,18,21$ and 24 hours).The experimental design was completely randomized and data were submitted to analysis of variance and regression. The evaluation of the treatment effects was based on the determination of moisture content, $\%$ of seed germination and vigor (first count and germination speed; seedling length and seedling dry weight). The initial moisture content was $36 \%$, which registered the highest germination percentage (97\%). This was reduced with the increase of drying periods, reaching only $38 \%$ after 9 hours of drying and subsequent even more drastic reduction. As for the germination speed, the highest value (2.93) occurred in the zero period of drying, the same occurring with the length and dry weight of seedlings, which were reduced drastically with increasing periods of drying. The T. guianensis seeds are recalcitrant, which lose their viability and vigor as their moisture content is reduced, the critical level of moisture below which there is total loss of viability is $16 \%$.
\end{abstract}

Index termos: cupiúva, recalcitrant seeds, native fruitful, moisture content.

${ }^{1}$ (Trabalho 208-11). Recebido em: 15-08-2011. Aceito para publicação em: 09-05-2012.

${ }^{2}$ Graduação em Agronomia, Departamento de Fitotecnia e Ciências Ambientais, Centro de Ciências Agrárias da Universidade Federal da Paraíba (CCA-UFPB). CEP: 58.397-000, Areia - PB. E-mails: sssantosagro@hotmail.com; patricia.s.gondim@hotmail.com ${ }^{3}$ Prof ${ }^{\text {as }}$. Drs. do DFCA/CCA/UFPB, Campus II, Areia - PB. E-mails: ednaursulino@cca.ufpb; lane@cca.ufpb.br

${ }^{4}$ Prof. Dr. da UFRPE/UAG, Garanhuns - PE. E-mail:maciof@yahoo.com.br 


\section{INTRODUÇÃO}

No Brasil, a área de mata nativa é considerável, com grande variedade de árvores frutíferas ainda pouco estudadas, muitas das quais com potencial de aproveitamento pouco explorado devido à falta de conhecimentos que permitam a implantação de pomares comerciais (KOHAMA et al., 2006). Embora as espécies nativas tenham grande potencial de utilização como frutíferas, na arborização urbana e em reflorestamentos, seu uso é limitado em função da carência de informações técnicas sobre o manejo de suas sementes (BARBEDO et al., 1998).

A espécie Tapirira guianensis Aubl. pertencente à família Anacardiaceae, é conhecida popularmente como cupiúva, tapiriri, guapiruba, cedrói, aroeirana, peito-de-pombo e camboatá, cuja árvore pode ser empregada em reflorestamento heterogêneo, principalmente de locais úmidos, graças à tolerância a esse ambiente e à produção de frutos muito procurados pela fauna. A madeira é muito empregada na confecção de brinquedos, compensados, embalagens e caixotarias leves, móveis comuns, saltos para calçados, cabos de vassoura (LORENZI, 2002).

Apesar de ser uma espécie de interesse econômico, pouco se sabe sobre a germinação de suas sementes após a desidratação, bem como sobre as condições favoráveis à conservação das mesmas. Há espécies que são sensíveis ao dessecamento, podendo as temperaturas agravar ainda mais o problema, influenciando na qualidade fisiológica da semente. Segundo Roberts (1973), quanto ao potencial de armazenamento, as sementes são classificadas em dois grupos: as sementes tolerantes à redução do grau de umidade e ao resfriamento foram denominadas de sementes ortodoxas, enquanto as outras, sensíveis, foram chamadas de sementes recalcitrantes.

A capacidade fisiológica de tolerância à dessecação pós-colheita das sementes é variável entre as espécies. A maioria possui sementes que toleram dessecação a teores de água próximos de 2 a $5 \%$, ou mesmo abaixo desses níveis, sendo denominadas ortodoxas, enquanto outras, que possuem sementes classificadas como 'intermediárias', toleram dessecação a teores de água em torno de 10 a $13 \%$ e têm a viabilidade reduzida em teores de água inferiores (FONSECA; FREIRE, 2003). As sementes de espécies que não toleram dessecação a teores de água entre 15 e $20 \%$ são classificadas como recalcitrantes (ROBERTS, 1973; HONG; ELLIS, 1996).

O teor de água é um fator determinante do comportamento das sementes recalcitrantes durante $o$ armazenamento. Nessas sementes, a água subcelular está fortemente associada às superficies macromo- leculares, assegurando, em parte, a estabilidade de membranas e macromoléculas. A perda de água estrutural durante o processo de secagem causaria a alteração de sistemas metabólicos e de membranas, resultando no início do processo de deterioração (FARRANT et al., 1988). O desenvolvimento das sementes recalcitrantes difere do das ortodoxas por não ter a fase de desidratação no ponto de maturidade fisiológica (FARRANT et al., 1988), ocorrendo um declínio do teor de água destas sementes, não sendo significativo quando comparado com a fase de desidratação das sementes ortodoxas (KIKUTI, 2000).

$\mathrm{O}$ desenvolvimento das sementes recalcitrantes difere das ortodoxas por não apresentar a fase de desidratação (FARRANT et al., 1988), ou seja, no ponto de maturidade fisiológica ocorre um declínio do teor de água das sementes, sendo, entretanto, não significativo quando comparado à fase de desidratação, propriamente dita, das sementes ortodoxas (KIKUTI, 2000).

As sementes recalcitrantes continuam hidratadas até o final do desenvolvimento e maturação (SCHMIDT, 2000; HARTMANN et al., 1997), geralmente com capacidade de germinarem imediatamente após a separação da planta-mãe, em função de seu elevado teor de água, sem a necessidade de hidratação adicional exógena. De forma geral, em nenhum momento do desenvolvimento dessas sementes se verifica tolerância à dessecação, motivo pelo qual as mesmas têm grande dificuldade em sua conservação (BARBEDO; MARCOS FILHO, 1998; HARTMANN et al., 1997).

A identificação do período de secagem ideal constitui-se numa ferramenta importante para a melhor conservação das sementes no que se refere ao armazenamento. Dessa forma, o presente trabalho foi desenvolvido com o objetivo de avaliar a qualidade fisiológica das sementes de T. guianensis submetidas a diferentes períodos de secagem, em condições de $40{ }^{\circ} \mathrm{C}$ em estufa.

\section{MATERIAL E MÉTODOS}

A pesquisa foi conduzida no Laboratório de Análise de Sementes, do Centro de Ciências Agrárias, da Universidade Federal da Paraíba (CCA - UFPB), em Areia - PB, com sementes de Tapirira guianensis Aublet, obtidas de frutos maduros, com coloração roxo-escura colhidos em oito plantas-matrizes, localizadas no CCA - UFPB. O beneficiamento foi realizado pelo despolpamento manual com auxílio de uma peneira e, em seguida, as sementes foram lavadas em água corrente para a retirada da mucila- 
gem remanescente.

Após o beneficiamento, as sementes foram postas sobre papel toalha e submetidas à secagem em estufa com circulação e renovação de ar, regulada a temperatura de $40{ }^{\circ} \mathrm{C}$, pelos seguintes períodos: 0 (sem secagem); 3; 6; 9; 12; 15; 18; 21 e 24 horas. Antes e após cada período de secagem, as sementes foram submetidas às seguintes determinações e testes.

Teor de água - Para sua determinação, foram tomadas quatro repetições, com 10 sementes cada, por período de secagem, sendo utilizado o método da estufa a $105 \pm 3{ }^{\circ} \mathrm{C}$, durante 24 horas (BRASIL, 2009), sendo os resultados expressos em porcentagem, em base úmida.

Germinação - Após cada período de secagem, foram retiradas amostras de 100 sementes, que foram postas para germinar. $\mathrm{O}$ substrato utilizado foi o papel toalha, onde as sementes foram distribuídas sobre duas folhas, cobertas com uma terceira e organizadas em forma de rolo. O papel foi umedecido com água destilada no volume $(\mathrm{mL})$ equivalente a 3 vezes o peso seco do substrato, sem adição posterior de água. O teste foi conduzido em germinador do tipo BOD regulado, com temperatura constante de $25^{\circ} \mathrm{C}$ e fotoperíodo de 8 horas-luz e 16 de escuro. As avaliações foram feitas diariamente, por um período de 14 dias; considerando-se como germinadas aquelas que emitiram raiz e parte aérea perfeitas (plântulas normais). Os resultados foram expressos em porcentagem.

Primeira contagem de germinação - $\mathrm{O}$ teste de primeira contagem foi realizado juntamente com o teste de germinação, com avaliação das plântulas normais no sétimo dia após a semeadura, cujos resultados foram em porcentagem.

Índice de velocidade de germinação - Foi realizado simultaneamente ao teste de germinação. Foram registradas contagens diárias, no mesmo horário, dos sete aos 14 dias, sendo o índice calculado de acordo com a fórmula

$$
I V G=\frac{G_{1}+G_{2}+\ldots+G_{n}}{N_{1}+N_{2}+\ldots+N_{n}}
$$

proposta por Maguire (1962), em que, IVG = índice velocidade de germinação; $\mathrm{G}_{1}, \mathrm{G}_{2}$ e $\mathrm{G}_{\mathrm{n}}=$ número de sementes germinadas a cada dia; $\mathrm{N}_{1}, \mathrm{~N}_{2}$ e $\mathrm{N}_{\mathrm{n}}=$ número de dias decorridos da semeadura a primeira, segunda até a última contagem.

Comprimento e massa seca de plântulas - Após a contagem final do teste de germinação, as plântulas normais foram submetidas a medições (da raiz à parte aérea), com auxílio de uma régua graduada em centímetros. Em seguida, essas plântulas foram postas em sacos de papel Kraft e levadas à estufa regulada a $65^{\circ} \mathrm{C}$ até atingirem peso constante
(48 horas). Decorrido esse período, foram pesadas em balança analítica com precisão de 0,001g. Os resultados foram expressos em $\mathrm{cm} /$ plântula e g/ plântula, respectivamente.

Delineamento experimental e análise estatística - $\mathrm{O}$ delineamento experimental utilizado foi o inteiramente ao acaso, com quatro repetições e 25 sementes por parcela. Os resultados foram submetidos à análise de variância e de regressão polinomial, em que se testaram os modelos linear e quadrático, selecionando-se para explicar os dados significativos e com maior coeficiente de determinação $\left(R^{2}\right)$.

\section{RESULTADOS E DISCUSSÃO}

De acordo com os dados da Figura 1, observou-se a relação entre o teor de água das sementes de Tapirira guianensis e os diferentes períodos de secagem. Foi constatado que as sementes se encontravam com um teor de água inicial em torno de $36 \%$, reduzindo drasticamente nas primeiras horas de secagem (0-9 horas) e atingindo $9 \%$ de umidade após 24 horas de secagem. Esta redução rápida do teor de água no início da dessecação pode ter ocorrido em função da maior quantidade de água nas camadas superficiais das sementes e, à medida que essa água foi sendo evaporada, o processo tornou-se mais lento, possivelmente devido à maior dificuldade de perda da água do interior das sementes, tornando o processo mais lento.

$\mathrm{O}$ processo de secagem adotado pode ser classificado como rápido (PAMMENTER et al., 1998), pois demandou 24 horas para que o teor de água inicial das sementes (36\%) fosse reduzido para $9 \%$, à temperatura de $40{ }^{\circ} \mathrm{C}$. De forma semelhante, Andrade et al. (2005) observaram que a redução no teor de água das sementes de Archontophoenix alexandrae foi mais intensa nos períodos iniciais de secagem, diminuindo gradativamente o percentual de redução com o aumento do período de secagem.

No momento da dispersão, pode-se observar que as sementes se encontravam com alto teor de água, o que, de acordo com Roberts e King (1980), é característico de sementes recalcitrantes, pois, ao contrário de sementes ortodoxas, as sementes recalcitrantes não passam por um dessecamento acentuado durante a maturação e/ou antecedendo a dispersão. Dessa forma, para essas sementes, não é observada a chamada fase I da embebição, caracterizada por rápida absorção de água durante a fase inicial do processo de germinação.

As sementes de T. guianensis que não foram submetidas à secagem (zero hora) foram responsá- 
veis pelos maiores percentuais de germinação (97\%) e, após esse período, registrou-se uma redução na porcentagem de germinação, para $37 \%$ com 9 horas de secagem (Figura 2).

Decorridas as 12 horas de secagem, as sementes atingiram $16 \%$ de umidade e perda total da germinação, sendo, portanto, este teor de umidade letal para a sua germinação; no entanto, pela linha de tendência, essa perda ocorreu próximo de 18 horas de secagem

A perda de água em sementes recalcitrantes desencadeia alguns processos deterioráveis, como a desnaturação de proteínas, alterações na atividade das enzimas peroxidases e danos no sistema de membranas, resultando na completa perda de sua viabilidade (NAUTIYAL; PUROHIT, 1985). A água é essencial para a integridade de estruturas intracelulares, portanto o metabolismo desequilibrado e os danos provocados devido à desidratação são as principais causas da perda de viabilidade das sementes durante a secagem (BERJAK; PAMMENTER, 2003).

Assim, os resultados obtidos podem ser devido à perda de água durante a fase de desidratação, pois a própria perda de volume das sementes pode ter resultado em danos mecânicos estruturais que não foram corrigidos durante a reidratação, no processo germinativo. Em sementes recalcitrantes, a água subcelular está fortemente associada às superfícies macromoleculares, assegurando, em parte, a estabilidade de membranas e macromoléculas (BOVI et al., 2004). Assim, a perda de água estrutural durante o processo de secagem de sementes recalcitrantes pode causar severas alterações dos sistemas metabólicos e de membranas, dando início ao processo de deterioração dessas sementes (FARRANT et al., 1988).

Resultados semelhantes foram observados em sementes de Araucaria angustifolia (Bert.) O. Ktze, e a perda do poder germinativo foi proporcional ao período de desidratação na câmara, comprovando que as mesmas são recalcitrantes (EIRA et al., 1994).

Reduções significativas na germinação de sementes Bactris gasipaes Kunthe (pupunha) iniciaram-se a partir de teores de água entre $28 \mathrm{e}$ 23\% (BOVI et al., 2004). As menores porcentagens de germinação (37\%) de sementes de Protium widgrenni Engler (almécega-vermelha) ocorreram quando as mesmas atingiram 13\% de água após a secagem (SEIFFERT et al., 2006).

De forma diferente, Delgado (2006) não constatou redução na germinação de sementes de Eugenia uniflora L. (pitanga) durante a desidratação.
Alves et al. (2008) também não verificaram redução na emergência de plântulas de Talisia esculenta (A. ST. Hil Radlk) (pitomba) quando suas sementes foram submetidas a secagem. Santos et al. (2010) verificaram que, durante o processo de secagem, a emergência de plântulas de Hancornia speciosa Gomes foi diminuindo gradativamente, atingindo $31 \%$ após 72 horas de secagem das sementes e, chegando a $12 \%$ após 144 horas.

Na primeira contagem de germinação, os percentuais máximos (62\%) também ocorreram nas sementes não desidratadas (zero hora de secagem), sendo que o percentual de germinação das sementes submetidas à secagem por nove horas foi de $7 \%$-+, não se verificando germinação a partir das 12 horas de secagem (Figura 3).

Resultados semelhantes foram obtidos com sementes Bactris gasipaes Kunth (BOVI et al., 2004) e de Talisia esculenta A. ST. Hil Radlk (ALVES et al., 2008), pois constatou-se que a redução do teor de água afetou negativamente o vigor, determinado pela primeira contagem de germinação.

Com relação ao vigor, determinado pelo índice de velocidade de germinação (IVG) (Figura 4), assim como na primeira contagem de germinação, também se verificou que os maiores índices $(2,93)$ foram atingidos pelas sementes que não foram submetidas à secagem (período zero), começando a reduzir drasticamente após este período e atingindo índices nulos às 12 horas de secagem. A deterioração causada pela desidratação das sementes também afetou o vigor, tornando a germinação mais lenta e diminuindo o crescimento das plântulas. A secagem, provavelmente, provocou danos aos tecidos vitais das sementes, como o embrião, o que explicaria a redução drástica da germinação e do vigor das sementes após períodos mais prolongados de secagem. Estes resultados demonstram o quanto uma secagem mais prolongada é prejudicial ao vigor das sementes de T. guianensis.

Quando células não tolerantes à dessecação são desidratadas, algumas consequências são observadas, tais como a possibilidade de seus solutos ficarem mais concentrados, aumentando as reações químicas destrutivas, podendo alguns desses solutos cristalizar, modificando a resistência das estruturas celulares (ANDRADE et al., 2005), o que provavelmente serve para explicar a drástica redução na velocidade de germinação de sementes de T. guianensis submetidas à desidratação.

De forma semelhante, a velocidade de germinação das sementes de Bactris gasipaes Kunth (pupunheira) (BOVI et al., 2004) e de Archantophoenix alexandrae Wendl and Drude (palmeira real) também reduziram em função da perda de água (ANDRADE et 
al., 2005). Quando as sementes de Protium widgrenii Engler (amescla-branca) foram dessecadas a 13\% de umidade, também houve uma redução significativa na velocidade de germinação, em relação àquelas sementes com 51\% de umidade (SEIFFERT et al., 2006)

$\mathrm{O}$ vigor das sementes de Cenostigma tocantinum Ducke foi afetado negativamente pelo método de secagem em câmara com circulação e renovação de ar, à temperatura de $35^{\circ} \mathrm{C}$ (GARCIA et al., 2008), enquanto Alves et al. (2008) verificaram redução no índice de velocidade de germinação das sementes de Talisia esculenta após 44 horas de secagem.

Para o comprimento das plântulas (Figura 5), observou-se que os maiores valores $(12,7 \mathrm{~cm})$ foram obtidos daquelas oriundas de sementes que não foram submetidas à secagem (período zero), reduzindo para $3 \mathrm{~cm}$ após 9 horas de secagem. Esse teste de vigor evidenciou que a qualidade fisiológica das mesmas foi significativamente prejudicada após as primeiras horas de secagem, reduziram sua viabilidade em virtude da rápida perda de água inicial.

Diferentemente, Pammenter et al. (1998) veri- ficaram que as sementes recalcitrantes de Ekebergia capensis, quando secas rapidamente, mantiveram a viabilidade próxima da ótima, enquanto a secagem lenta levou à perda completa da viabilidade. Para $\mathrm{Ta}$ lisia esculenta (A. ST. Hil) Radlk, Alves et al. (2008) verificaram redução no comprimento das plântulas oriundas de sementes submetidas à secagem natural a uma temperatura de $27^{\circ} \mathrm{C}$ por até 120 horas.

À semelhança do comprimento de plântulas, a massa seca também se reduziu significativamente com o aumento dos períodos de secagem, alcançando valor máximo $(0,024 \mathrm{~g})$ no período zero de secagem e reduzindo para $0,005 \mathrm{~g}$ após nove horas de secagem (Figura 6).

Pelas variáveis analisadas, verificou-se que a secagem afetou o vigor das sementes, demonstrando que elas são sensíveis à dessecação. Estes resultados estão de acordo com os encontrado por Alves et al. (2008) em sementes de Talisia esculenta, quando observaram que períodos prolongados de secagem causaram efeitos fisiológicos prejudiciais na massa seca de plântulas.

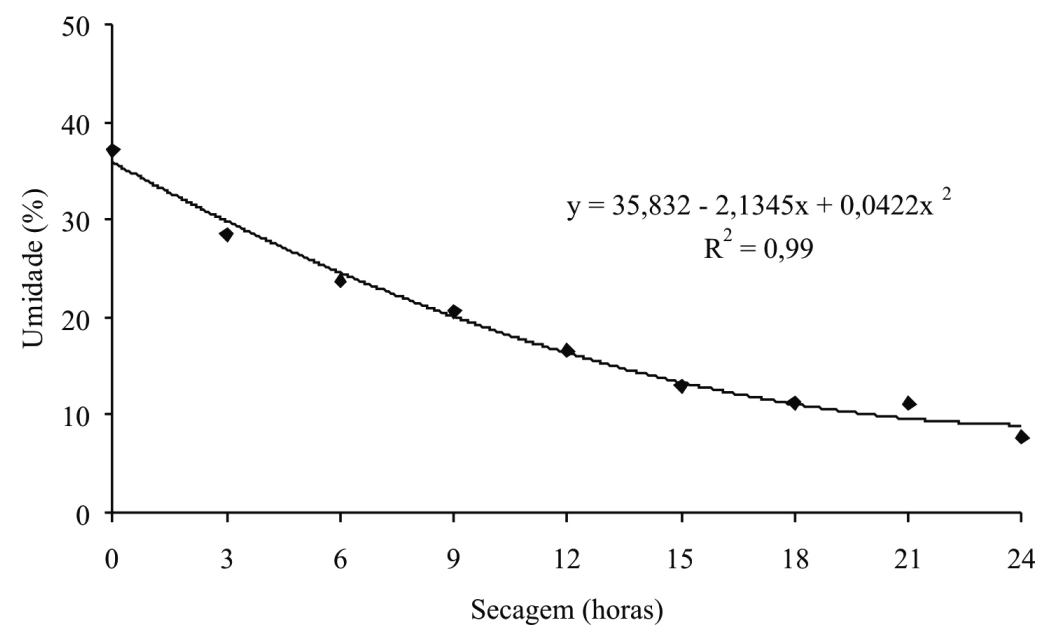

FIGURA 1 -Teor de água de sementes de Tapirira guianensis submetidas a diferentes períodos de secagem. 


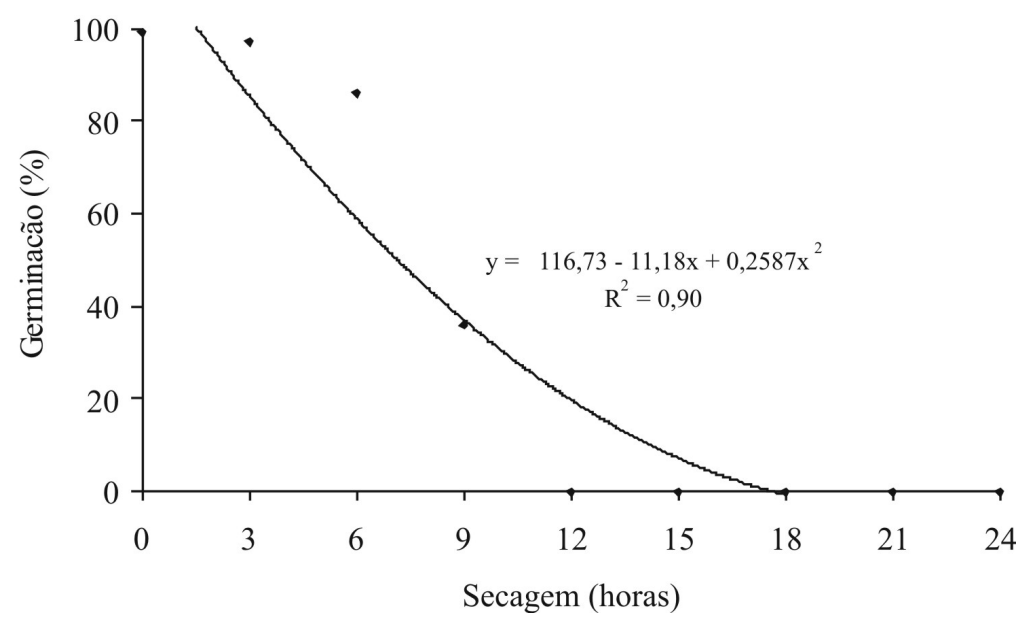

FIGURA 2 - Germinação de sementes de Tapirira guianensis submetidas a diferentes períodos de secagem.

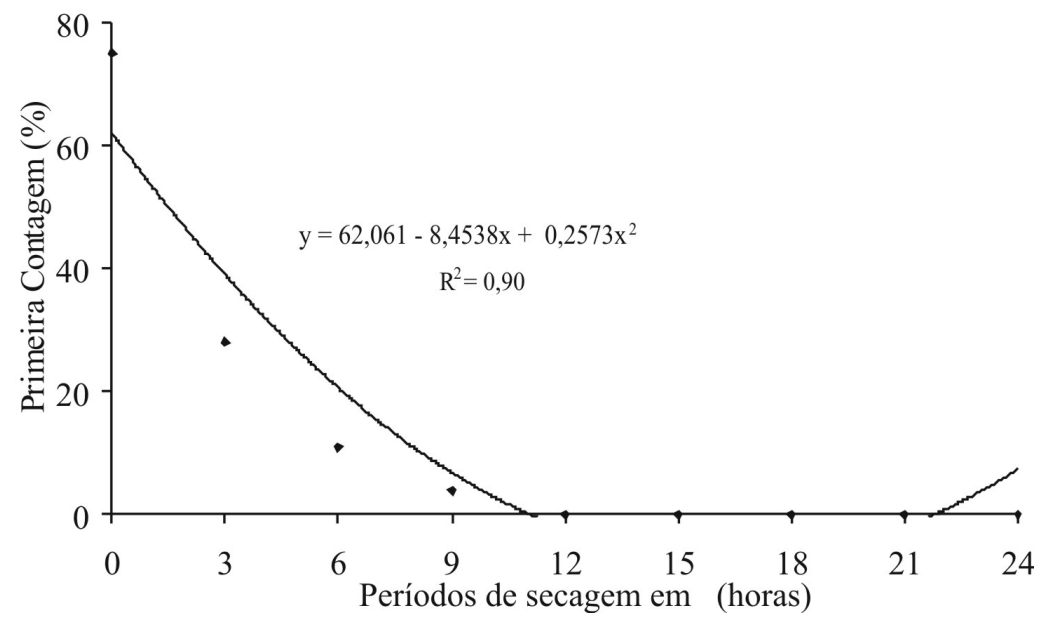

FIGURA 3 - Primeira contagem de germinação de sementes de Tapirira guianensis submetidas a diferentes períodos de secagem.

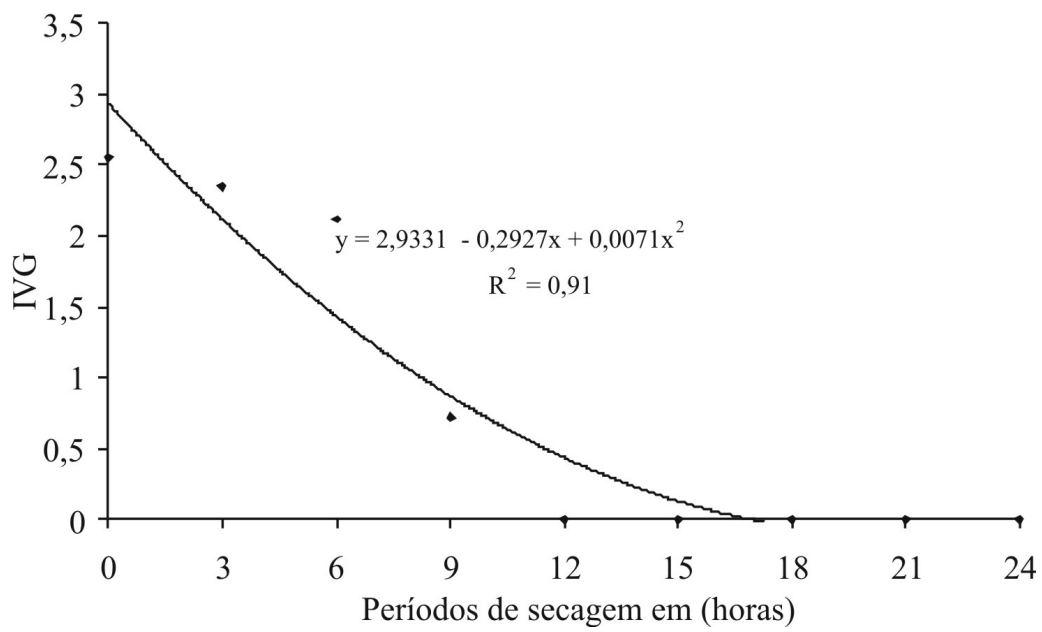

FIGURA 4- Índice de velocidade de germinação (IVG) de sementes de Tapirira guianensis submetidas a diferentes períodos de secagem. 


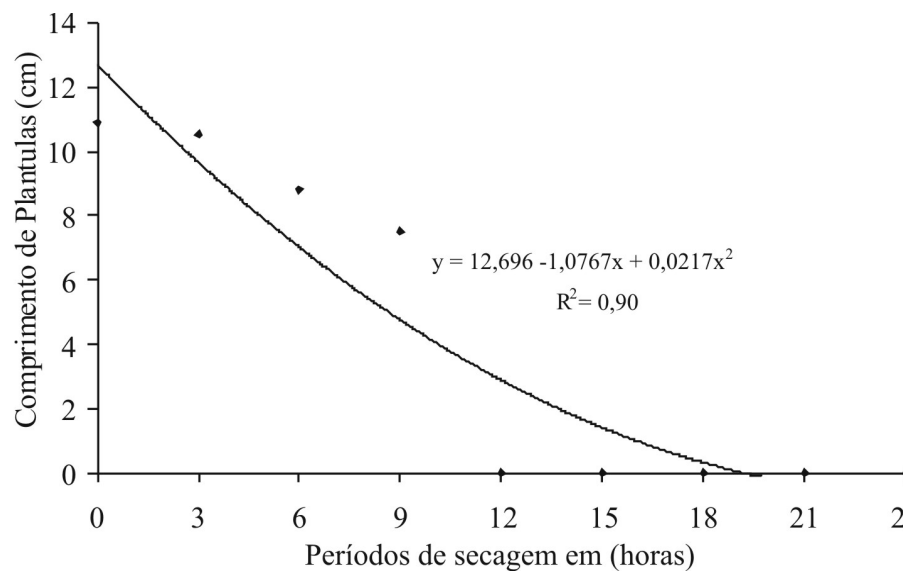

FIGURA 5 - Comprimento de plântulas de Tapirira guianensis oriundas de sementes submetidas a diferentes períodos de secagem.

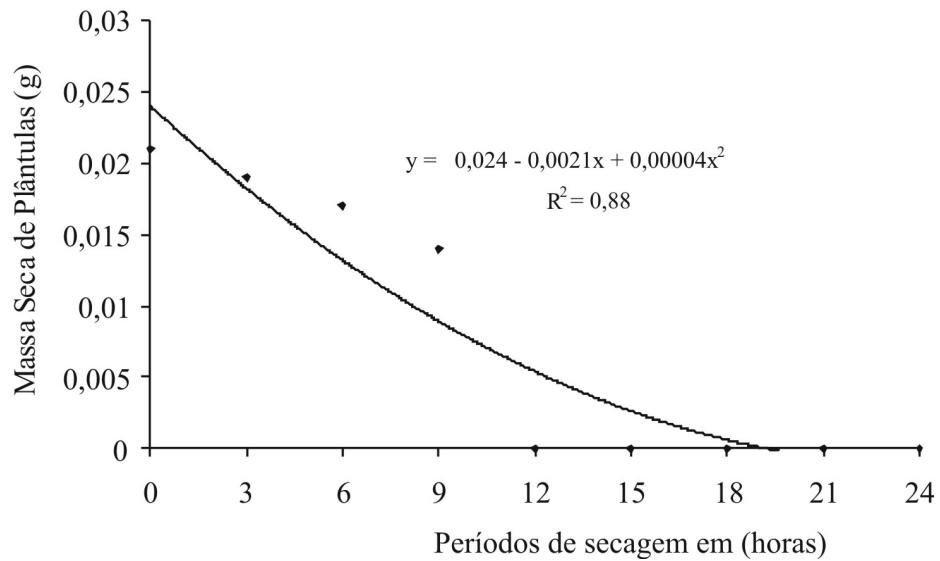

FIGURA 6 - Massa seca de plântulas de Tapirira guianensis oriundas de sementes submetidas a diferentes períodos de secagem.

\section{CONCLUSÕES}

1-As sementes da espécie Tapirira guianensis Aublet comportam-se como recalcitrantes, perdendo a viabilidade e o vigor à medida que seu teor de água é reduzido.

2-O nível crítico de água, abaixo do qual há perda total de viabilidade, está em torno de $16 \%$.

3-A secagem à temperatura de $40{ }^{\circ} \mathrm{C}$ até o período de 6 horas, quando o teor de água é de $24 \%$, mantém alta viabilidade das sementes de $T$. guianensis.

\section{REFERÊNCIAS}

ALVES, E.U.; SILVA, K.B.; BRUNO, R.L.A.; , A.U.; CARDOSO, E.A.; GONÇALVES, E.P.; BRAZ, M.S.S. Comportamento fisiológico de sementes de pitombeira [Talisia esculenta (A. ST. Hil) Radlk] submetidas à desidratação. Revista Brasileira de Fruticultura, Jaboticabal, v.30, n.2, p.509-516, 2008.

ANDRADE, R.R.; SCHORN, L.A.; NOGUEIRA, A.C. Tolerância à dessecação em sementes de Archantophoenix alexandrae Wendl. And Drude (palmeira real australiana). Ambiência, Guarapuava, v.1, n.2, p.279-288, 2005. 
BARBEDO, C.J.; KOHAMA, S.; MALUF, A.M.; BILIA, D.A.C. Germinação e armazenamento de diásporos de cerejeira (Eugenia involucrata DC. - Myrtaceae) em função do teor de água. Revista Brasileira de Sementes, Brasília, v.20, n.1, p.184188, 1998.

BARBEDO, C.J.; MARCOS FILHO, J. Tolerância à dessecação em sementes. Acta Botanica Brasilica, São Paulo, v.12, n.2, p.145-164, 1998.

BERJAK, P.; PAMMENTER, N.W. Chapter 4: Orthodox and recalcitrant seeds. In: VOZZO, J.A. Tropical tree seed manual. Washington: USDA Forest Science, 2003. p.137-147.

BOVI, M.L.A.; MARTINS, C.C.; SPIERING, S.H. Desidratação de sementes de quatro lotes de pupunheira: efeitos sobre a germinação e o vigor. Horticultura Brasileira, Brasília, v.22, n.1, p.109112, 2004.

BRASIL. Ministério da Agricultura, Pecuária e Abastecimento. Regras para análise de sementes. Brasília: Secretaria de Defesa Agropecuária. Brasília, 2009. 395p.

DELGADO, L.F. Tolerância à dessecação em sementes de espécies brasileiras de Eugenia. 2006. 96f. Dissertação (Mestrado em Biodiversidade Vegetal e Meio Ambiente) - Instituto de Botânica da Secretaria do Meio Ambiente, São Paulo, 2006

EIRA, M.T.S.; SALOMÃO, A.N.; CUNHA, R.; CARRARA, D.K.; MELLO, C.M.C. Efeito do teor de água sobre a germinação de sementes de Araucaria angustifolia (Bert.) O. Ktze. Araucariaceae. Revista Brasileira de Sementes, Brasília, v.6, n.1, p.71-75, 1994.

FARRANT, J.M.; PAMMENTER, N.W.; BERJAK, P. Recalcitrance: a current assessment. Seed Science and Technology, Zurich, v.16, n.1, p.155-166, 1988.

FONSECA, S.C.L.; FREIRE, H.B. Sementes recalcitrantes: problemas na pós-colheita. Bragantia, Campinas, v.62, n.2, p.297-303, 2003.

GARCIA, L.C.; MORAES, R.P.; LIMA, R.M.B. Determinação do grau crítico de umidade em sementes de Cenostigma tocantinum Ducke. Revista Brasileira de Sementes, Lavras, v.30, n.3, p.172-176, 2008.
HARTMANN, T.H.; KESTER, D.E.; DAVIES, F.T.; GENEVE, R. Plant propagation: principles and practices. $6^{\text {th }}$ ed. New Jersey: Prentice Hall, 1997. p.549-622.

HONG, T.D.; ELLIS, R.H. A protocol to determine seed storage behavior. Rome: International Plant Genetic Resources Institute, 1996. 62p. (Technical Bulletin, 1).

KIKUTI, A.L.P. Aplicação de antioxidantes em sementes de cafeeiro visando à preservação da qualidade. 2000. 72f. Dissertação (Mestrado) - Universidade Federal de Lavras, Lavras, 2000.

KOHAMA, S.; MALUF, A.M.; BILIA, D.A.C.; BARBEDO, C.J. Secagem e armazenamento de sementes de Eugenia brasiliensis Lam. (grumixameira). Revista Brasileira de Sementes, Pelotas, v.28, n.1, p.72-78, 2006.

LORENZI, H. Árvores brasileiras: manual de identificação e de cultivo de plantas arbóreas do Brasil. 4.ed. São Paulo: Nova Odessa, 2002. 368p.

MAGUIRE, J.D. Speed of germination: aid in selection and evaluation for seedling emergence and vigour. Crop Science, Madison, v.2, n.2, p.176-177, 1962.

NAUTIYAL, A.R.; PUROHIT, A.N. Seed viability in sal. II. Physiological and biochemical aspects of ageing in seeds of Shorea robusta. Seed Science and Technology, Zurich, v.13, n.1, p.69-76, 1985.

PAMMENTER, N.W.; GREGGAINS, V.; KIOKO, J.I.; WESLEY-SMITH, J.; BERJAK, P.; FINCHSAVAGE, W.E. Effects of differential drying rates on viability retention of recalcitrant seeds of Ekebergia capensis. Seed Science Research, Wallingford, v.8, n.4, p.463-471, 1998.

ROBERTS, E.H. Predicting the storage life of seeds. Seed Science and Technology, Zurich, v.1, n.3, p.499-514, 1973.

ROBERTS, E.H.; KING, M.W. The characteristics of recalcitrant seeds. In: CHIN, H.F.; ROBERTS, E.H. Recalcitrant crop seeds. Kuala Lumpur: Tropical Press, 1980. p.1-5. 
SANTOS, P.C.G.; ALVES, E.U.; GUEDES, R.S.; SILVA, K.B.; CARDOSO, E.A.; LIMA, C.R. Qualidade de sementes de Hancornia speciosa Gomes em função do tempo de secagem. Semina: Ciências Agrárias, Londrina, v.31, n.2, p.343-352, 2010.

SCHMIDT, L. Guide to handling of tropical and subtropical forest seed. Humlebaek: Danida Forest Seed Centre, 2000. p.225-261.

SEIFFERT, M.; ALVARENGA, A. A.; GUIMARÃES, R. M.; CASTRO, E.M.; CARDOSO, M.G.; PAIVA, R.; DOUSSEAU, S.; VIEIRA, C.V. Efeito da secagem e de diferentes temperaturas na germinação de sementes de Protium widgrenii Engler. Ciência e Agrotecnologia, Lavras, v.30, n.1, p.35-42, 2006. 